\title{
Intrasellar Cavernous Hemangioma: MRI Findings of a Very Rare Lesion
}

\author{
Aynur Turan ${ }^{\mathrm{a}, \mathrm{c}}$, Havva Akmaz Unlu ${ }^{\mathrm{a}}$, Hasan Yigit ${ }^{\mathrm{a}}$, Omer Yilmaz ${ }^{\mathrm{a}}$, Zeynep Ilerisoy Yakut ${ }^{\mathrm{b}}$
}

\begin{abstract}
Intrasellar cavernous hemangioma is an extremely rare lesion. It is usually confused with pituitary adenoma, both clinically and radiologically. It is important to differentiate intrasellar cavernous hemangioma from pituitary tumors because of the risk of severe hemorrhage during operation and the possible complications in the postoperative period. Magnetic resonance imaging characteristics of the lesion may be helpful in differential diagnosis. In this report, we present the magnetic resonance imaging findings of a cavernous hemangioma case, which is totally intrasellar located.
\end{abstract}

Keywords: Cavernous hemangioma; Pituitary tumor; Magnetic resonance imaging

\section{Introduction}

Intrasellar cavernous hemangiomas $(\mathrm{CH})$ are extremely rare; to our knowledge, there are only a few cases reported in the literature [1-5]. CHs account for $5-13 \%$ of the intracranial vascular malformations. Although they can occur in all parts of the nervous system, most often these lesions occur in the cerebral hemispheres and typically present with seizures and bleeding $[1,6]$. CH is a rare vascular lesion of the sellar region. The radiological and neuroophthamological features are similar to a pituitary adenoma. Magnetic resonance imaging (MRI) characteristics of an intrasellar $\mathrm{CH}$ were report-

Manuscript accepted for publication September 11, 2013

\footnotetext{
a Department of Radiology, Ankara Training and Research Hospital, Ankara, Turkey

${ }^{\mathrm{b}}$ Department of Radiology, Ankara Ataturk Training and Research Hospital, Ankara, Turkey

${ }^{\mathrm{c}}$ Corresponding author: Aynur Turan, Diskapi Egitim ve Arastırma Hastanesi, Radyoloji Bolumu, 06010, Etlik, Ankara, Turkey.

Email:aynur_turan@yahoo.co.uk
}

doi: http://dx.doi.org/10.4021/jmc1485w ed in only two cases and can mimic pituitary adenoma $[1,3]$.

In this article, we present case report of a patient, who was first evaluated as pituitary macroadenoma preoperatively but retrospectively was noticed to be a case of $\mathrm{CH}$ which has distinctive features from other lesions of sella.

\section{Case Report}

A 32-year-old female patient was admitted to our hospital for blurred vision continuing nearly for one month. All the biochemical and endocrinological tests were in normal ranges. No pathological finding was observed in vision field and neurological examination.

In the MRI analysis, a solid lesion with $22 \mathrm{~mm} \times 18 \mathrm{~mm}$ $\times 22 \mathrm{~mm}$ dimensions was expanding sella, showing extension to suprasellar cistern, compressing optic chiasma and hypointense in T1WI (Fig. 1A), markedly hyperintense in T2WI (Fig. 2) and markedly contrast enhanced (Fig. 1C). It was evaluated as non-functioning hypophysis macroadenoma. Trans-sphenoidal subtotal mass resection was performed and there were no complications during the operation. In the postoperative period, transient Diabetes Insipidus (DI) had occurred. The histopathological diagnosis was $\mathrm{CH}$. It was remarkable that retrospectively the lesion was markedly hyperintense in T2WI and contained areas of signal void indicating presence of vascular structure (Fig. 2). Although dynamic study was not performed, during the hypophysis and cranial MRI analysis, more than one contrast-enhanced series were taken sequentially. It was remarkable that in the first series the lesion was peripheral (Fig. 1B) and in the following series completely marked contrast-enhanced (Fig. $1 \mathrm{C)}$.

\section{Discussion}

$\mathrm{CH}$ is more a hamartoma or vascular malformation rather than a neoplasia [3]. Although $\mathrm{CH}$ is very rare, $\mathrm{CH}$ of the cavernous sinus present like tumors and there can be a medial extension into the sella [7]. This growth pattern is differentiated from intrasellar $\mathrm{CH}$ with cavernous sinus extension 


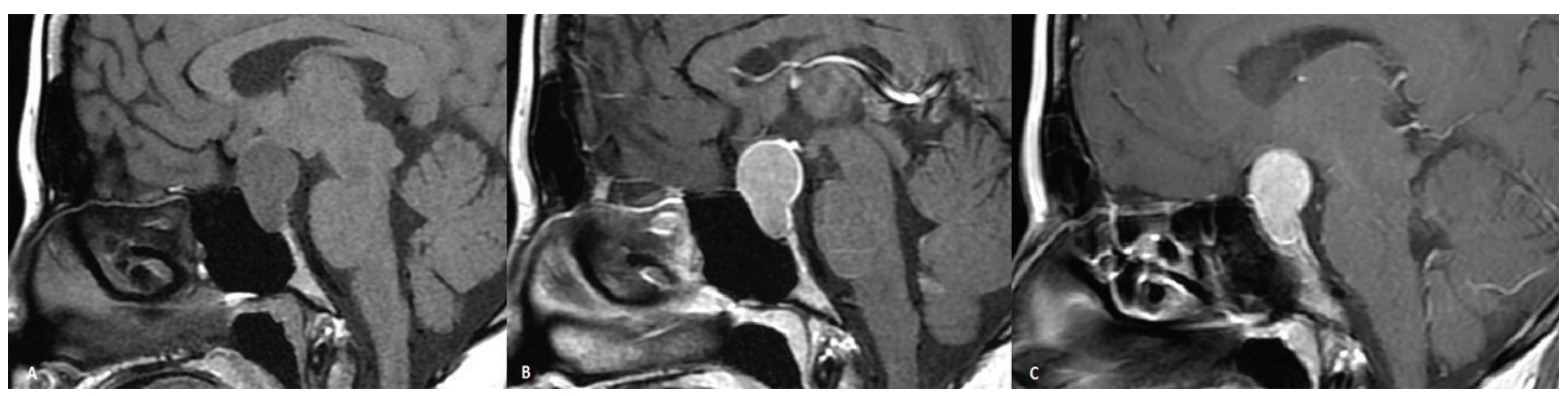

Figure 1. A) Sagittal pre-contrast T1WI shows mild hypointensity, B) post-contrast T1WI MRI showing peripheral contrast enhancement in the first series, and C) homogen contrast enhancement is observed in the subsequent series.

by measuring the major portion of the tumor mass. In our case, hemangioma was located in the sella and there was no cavernous sinus extension.

Intrasellar CH's may be symptomatic or asymptomatic. In the literature, besides asymptomatic cases one of which was found during autopsy [4] and another found incidentally, cranial nerve palsies caused by cavernous sinus extension $[3,7,8]$ or secondary vision problems due to optic chiasm compression [9] were reported.

Except from the case reported by Nagai et al [10], which was not diagnosed histopathologically and was thought as intrasellar CH with only clinical and MRI findings, there are only two studies describing MRI findings of intrasellar $\mathrm{CH}$. Cobbs et al [1] presented a case of intrasellar $\mathrm{CH}$ which was operated under the diagnosis of adenoma and had complications of subaracnoidal hemorrhage and rhinorrhea. In this report, T2 signal characteristics in MRI findings were not mentioned and they declared development of moderate homogeneous enhancement in post-contrast T1WI. Likewise, in the intrasellar $\mathrm{CH}$ case, which also had cavernous sinus extension reported by Chuang et al [3], T2 signal characteristics were mentioned and hypointense to grey matter on T1WI and homogenous enhancement after contrast administration were reported. Although T2 WI characteristics were mentioned in parasellar $\mathrm{CHs}$ in the literature, no definition of $\mathrm{T} 2$ signal characteristics of intrasellar $\mathrm{CH}$ was made before our case. The reason for this is thought to be the exclusion of

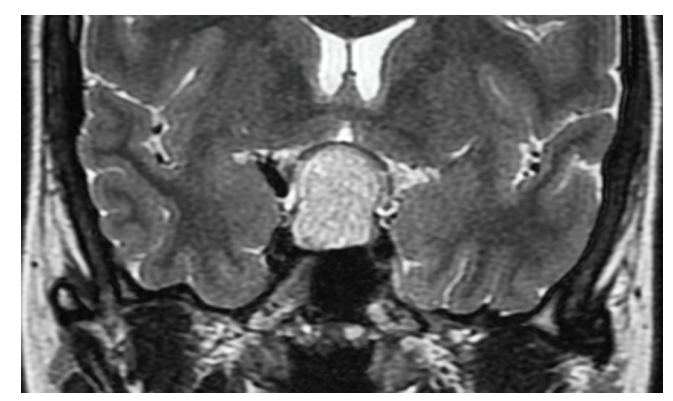

Figure 2. Coronal T2WI MRI showing hyperintense mass in the sella including hypointense areas of signal void indicating vascular structures.
T2 WI in routine hypophysis MRI.

One case of cavernous sinus $\mathrm{CH}$ was reported as marked T2 with hyperintensity with some signal void structures [9]. In our case, marked hyperintensity in T2WI and signal void structures consistent with vascular origin were noticeable.

In the differential diagnosis of mass lesions in sellar region, dynamic studies may give extra information [11]. This lesion initially is peripherally and then progressively totally homogeneous contrast enhanced. This contrast pattern is similar to other extra-cranial $\mathrm{CH}$ cases such as liver $\mathrm{CHs}$ [12]. In the literature, it was reported that while in a cavernous sinus $\mathrm{CH}$, in coronal image, patchy peripheral contrast enhancement was observed, in axial image homogeneous contrast was enhanced [13].

In our case, similar MRI findings were noticeable. In first contrast administration series, the lesion was peripherally contrast enhanced while in continuing series it was marked homogeneously contrast enhanced.

Many neoplasms, such as meningioma, optic glioma, craniopharyngioma, germinoma, and $\mathrm{CH}$ develop in the sellar and parasellar regions, while large pituitary adenomas with para or supra-sellar extension are often difficult to differentiate from other tumors.

As the sellar $\mathrm{CHs}$ are dura based, complete resection may cause severe hemorrhage. For this reason, if intrasellar $\mathrm{CH}$ is suspected, only partial resection should be performed. Stereotactic radiosurgery may also be used in treatment [1].

In the differential diagnosis of mass lesions in the sellar region, although seen rarely, $\mathrm{CHs}$ should be taken into consideration because of high complication risks both during and after operation. T2WI signal characteristics of these kinds of lesions may be instructive. Marked hyperintensity in T2WI and presence of signal void areas may suggest $\mathrm{CH}$. The dynamic studies of contrast administration may contribute in the differential diagnosis of mass lesions located in these regions.

\section{Conflict of Interest}

Authors declare no conflict of interest. 


\section{References}

1. Cobbs CS, Wilson CB. Intrasellar cavernous hemangioma. Case report. J Neurosurg. 2001;94(3):520-522.

2. Buonaguidi R, Canapicci R, Mimassi N, Ferdeghini M. Intrasellar cavernous hemangioma. Neurosurgery. 1984;14(6):732-734.

3. Chuang CC, Jung SM, Yang JT, Chang CN, Pai PC. Intrasellar cavernous hemangioma. J Clin Neurosci. 2006;13(6):672-675.

4. Sansone ME, Liwnicz BH, Mandybur TI. Giant pituitary cavernous hemangioma: case report. J Neurosurg. 1980;53(1):124-126.

5. Mitsuhashi T, Hashimoto R, Nagahama S, Nagata Y. Intrasellar cavernous angioma in neurofibromatosis. Hum Pathol. 1991;22(6):623-624.

6. Cosar M, Iplikcioglu AC, Gokduman CA, Bek S, Hatipoglu MA. Cavernous sinus Hemangiomas: Two Case Reports. Turkish Neurosurgery. 2005;15(3):123-128.

7. Lombardi D, Giovanelli M, de Tribolet N. Sellar and parasellar extra-axial cavernous hemangiomas. Acta Neurochir (Wien). 1994;130(1-4):47-54.

8. Chhang WH, Khosla VK, Radotra BD, Kak VK. Large cavernous haemangioma of the pituitary fossa: a case report. Br J Neurosurg. 1991;5(6):627-629.

9. Yao Z, Feng X, Chen X, Zee C. Magnetic resonance imaging characteristics with pathological correlation of cavernous malformation in cavernous sinus. J Comput Assist Tomogr. 2006;30(6):975-979.

10. Nagai S, Shimizu C, Kimura Y, Umetsu M, Taniguchi S, Takeuchi J, Atsumi T, et al. A case of reversed pituitary dysfunction with intrasellar mass. J Endocrinol Invest. 2006;29(4):367-372.

11. Suzuki M, Matsui O, Ueda F, Matsushita T, Fujinaga Y, Kobayashi K, Horichi Y, et al. Dynamic MR imaging for diagnosis of lesions adjacent to pituitary gland. Eur J Radiol. 2005;53(2):159-167.

12. Hayashi Y, Tachibana O, Mohri M, Kinoshita M, Hayashi Y, Yoshinaga T, Hamada Ji. Uncommon co-localisation of pituitary adenoma and parasellar cavernous hemangioma. Eur J Radiol. 2008;66:e1-e3.

13. Salanitri GC, Stuckey SL, Murphy M. Extracerebral cavernous hemangioma of the cavernous sinus: diagnosis with MR imaging and labeled red cell blood pool scintigraphy. AJNR Am J Neuroradiol. 2004;25(2):280284. 